\title{
Shortening average trip times by adjusting stopping and overtaking train stations
}

\author{
T. Katori, H. Kabumoto \& T. Izumi \\ Nihon University, Japan
}

\begin{abstract}
We are studying railway operation optimization. Two kinds of trains, local and rapid, are under consideration to investigate the optimization of rapid trains stopping stations by adjusting the stopping stations to reach optimum convenience and rapidity. However, the rapid train has to overtake local trains that are running ahead. Therefore, overtaking facilities need to be considered too.

In this paper, we describe the relation between stopping and overtaking station combinations and operation effectiveness. First, the rapid train stopping and overtaking stations are determined by DP (Dynamic Programming), considering real overtaking facilities at stations. Second, the rapid train timetable is determined and drawn on the train diagram. Third, the local train timetable is determined based on overtaking stations. The diagram is drawn for both directions starting from the overtaking station. The evaluation value is the average trip time, and is calculated by the timetable (diagram) and the passenger OD (Origin and Destination) table. By computer simulation using an existing line, we show that the most effective conditions are fewer overtaking stations, and no simultaneous overtaking at a stopping station.

Keywords: rapid trains, combination of stopping and overtaking at stations, train timetable, average trip time.
\end{abstract}

\section{Introduction}

Train trip time can in general be shortened by improving brake performance, the tracks and the signal system. These improvements are all hardware related. On the other hand, improving the train timetable (diagram) belongs to the software field. This software approach is more cost-efficient than the hardware approach. 
This approach includes shortening the waiting time at transfers, shortening intervals between trains, and so on.

Therefore, we are studying shortening the required trip time by improving the train diagram. Our main goal is to set appropriate stopping stations for rapid trains. Rapid trains are operated on most main Japanese lines, but the stopping stations are not the most suitable.

In this study, we try to optimize the stopping stations for rapid trains. Two kinds of trains are under consideration, local and rapid, and the rapid train has to overtake the local train that is running ahead. Therefore, for actual operation, overtaking facilities have to be considered.

In this paper, we describe how to shorten the average trip time for passengers. To this purpose, we adjusted the rapid train stopping and overtaking stations on an existing line, as well as the overtaking facilities.

\section{Rapid train operation}

\subsection{Adjusting rapid train stopping stations}

As for possible combinations, at each station:

- $\quad$ the rapid train stops or passes;

- $\quad$ the rapid train overtakes or does not overtake the local one running ahead.

The above combination allows for four patterns. When there are $\mathrm{N}$ stations on the line, the number of combinations is $4^{\mathrm{n}-2}$. If only existing overtaking facilities are considered, the number is $2^{\mathrm{n}-2}$. In the algorithm research field, computation time complexity is expressed as equation (1).

$$
\mathrm{O}\left(2^{\mathrm{n}-2}\right)=\mathrm{O}\left(2^{\mathrm{n}}\right)
$$

This problem cannot be solved by round robin.

For this problem, we have tried to determine the stopping stations based on the number of passengers, or by using a genetic algorithm. However, we still could not determine the best combination of stations.

In this paper, we use existing overtaking facilities. Rapid train stopping stations are determined by dynamic programming (DP), a combination of solutions is selected from possible operations. By DP, the computation time complexity decreases $\mathrm{O}\left(\mathrm{n}^{3}\right)$, the problem is solved in real time. If the overtaking stations are also determined by DP, the computation time complexity is $\mathrm{O}\left(\mathrm{n}^{6}\right)$.

\subsection{Assumptions for rapid trains operation}

- The kinds of trains under consideration are rapid and local trains only. The stations where rapid trains stop or overtake the local ones are static.

- The train timetable repeats the same pattern every departure cycle.

- The line under consideration has a double track, and rapid trains can overtake the local train at the station only.

- All trains reach the terminal station. No train turns along the way. 
- The minimum gap time on the diagram is two minutes, and the trains' stopping time is greater than, or equal to one minute. Rapid trains can shorten stopping time at the stations only, but cannot shorten running time between stations.

- $\quad$ No special fare is required to be paid by passengers, i.e. there is no trade off between cost and time.

- All passengers reach their destination by moving only one way.

- All passengers who can shorten their trip time by changing trains on the same line do so.

- All trains have the same driving performance.

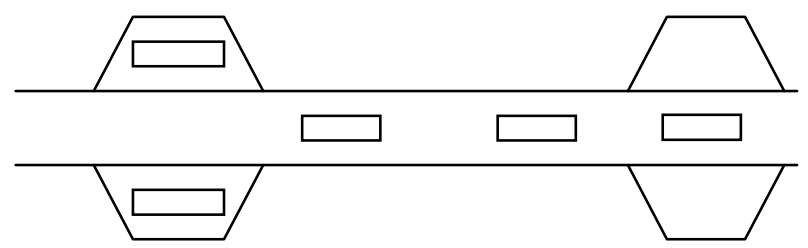

Figure 1: Concept of track layout.

Departure cycle, Minimum gap time (2 min) $\rightarrow$ time

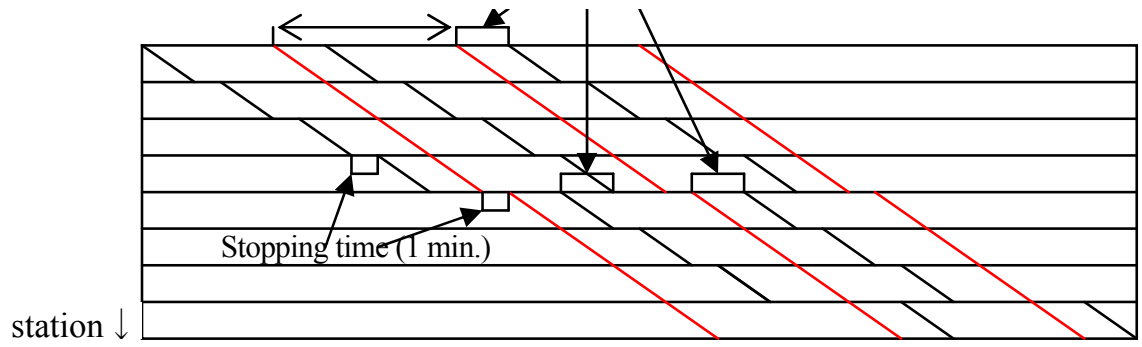

Figure 2: Train diagram sample to explain conditions.

\subsection{Evaluation value}

The aim of this study is to shorten the average trip time, when the combination of the rapid train stopping and overtaking stations is adjusted optimally. The evaluation value is the average trip time, shown by equation (2).

$$
\text { Evaluation value (average trip time) }=\frac{\sum_{\mathrm{t}} \Sigma_{\mathrm{i}} \Sigma_{\mathrm{i}} \mathrm{OD}(\mathrm{i}, \mathrm{j}, \mathrm{t}) * \mathrm{rt}(\mathrm{i}, \mathrm{j}, \mathrm{t})}{\sum_{\mathrm{t}} \Sigma_{\mathrm{i}} \Sigma_{\mathrm{j}} \mathrm{OD}(\mathrm{i}, \mathrm{j}, \mathrm{t})}
$$

OD $(i, j, t)$ : number of passengers from station No. $i$ to No. $j$ at time $t$. $\operatorname{rt}(\mathrm{i}, \mathrm{j}, \mathrm{t})$ : required time to move from station No. $\mathrm{i}$ to No. $\mathrm{j}$ at time $\mathrm{t}$. This moving time includes waiting time. 
The smaller the value becomes, the more appropriate the station combination is and the more trip time can be shortened.

\section{Rapid and local train diagram (timetable) generation}

\subsection{Determination of rapid train stopping station combinations}

Rapid train stopping and overtaking stations are determined by dynamic programming in three dimensions. So, the three axes mean the stopping, overtaking and the number of stations, respectively. The evaluation value (average trip time) is calculated in this space, and the combination that has the smallest value is renewed and saved with the value. Figure 3 shows this concept.

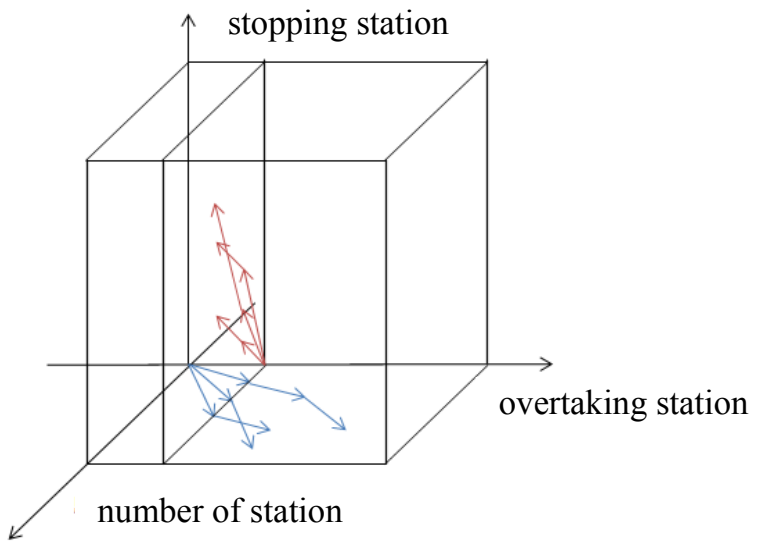

Figure 3: Concept of DP in three dimensions.

The dynamic programming in this study means a method to realize many combinations, but, unfortunately, each solution is not guaranteed to be the best one.

\subsection{Adjusting rapid train stopping stations}

Rapid train stopping stations are determined by DP. On the other hand, the overtaking stations are determined by considering existing facilities.

The combinations of rapid train stopping and overtaking stations include possible and impossible operations. This is judged by assumptions 2.2:

- Minimum gap time on the diagram is two minutes, and the trains' stopping time is greater than, or equal to one minute.

The conditions for a rapid train overtaking a local one are as follows.

- When a rapid train stops at a station, and passengers change from a local to a rapid train, more than three passing stations are needed between overtaking stations. 
- When a rapid train passes a station, more than two stations are needed between overtaking stations.

If the above conditions are not fulfilled, then the trains cannot operate because the minimum interval time between the trains is not maintained.

\subsection{Conversion to train diagram}

The train diagram reflects possible operations.

First, the rapid train diagram is drawn. Next, the local train diagrams are drawn starting from overtaking stations. In this paper, a local train is overtaken only once. When a rapid train has some overtaking stations, the local train diagram is drawn starting from each overtaking station in both directions.

Figure 4 shows this procedure. Figure 4(a) shows the rapid train diagram based on the combinations attained after adjusting the stopping stations. Figure 4(b) shows the local train diagram starting from the overtaking station in

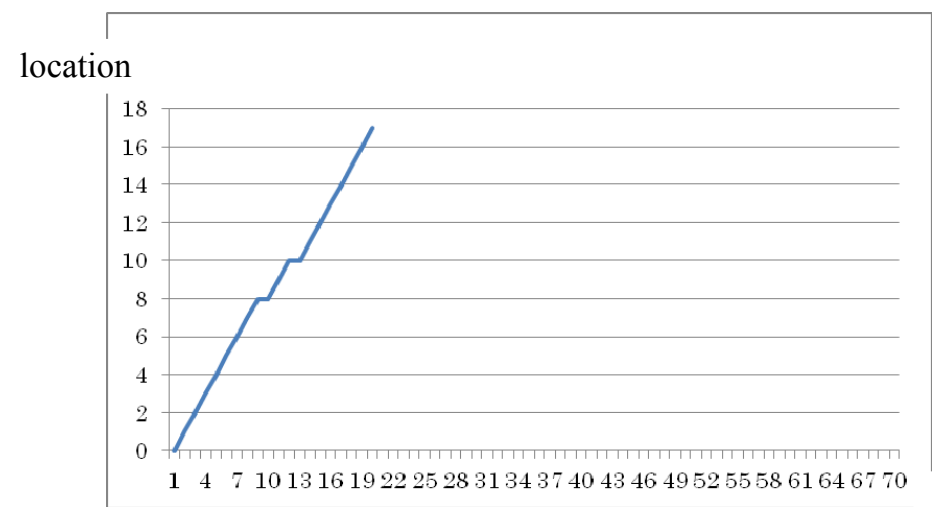

(a) Rapid train diagram.

time

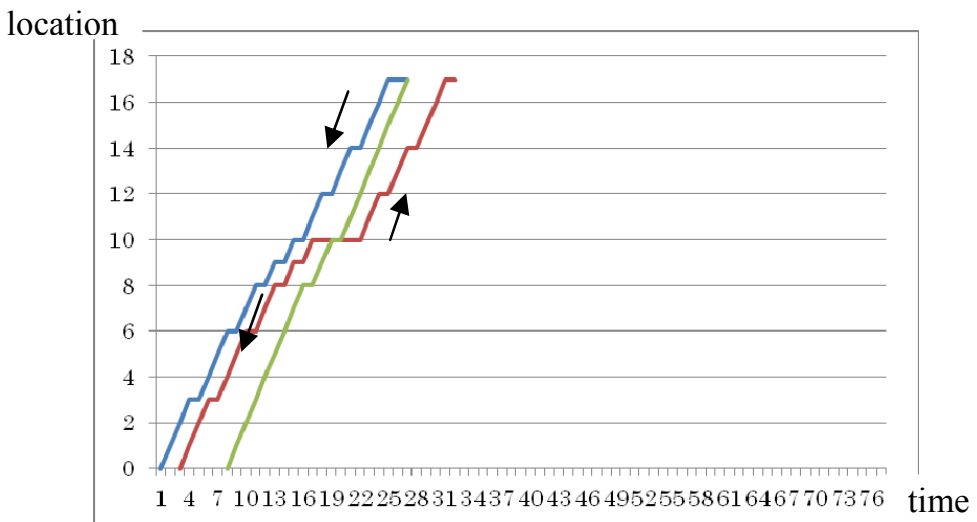

(b) Local train diagram in both directions starting from overtaking stations.

Figure 4: Train diagram drawing process. 


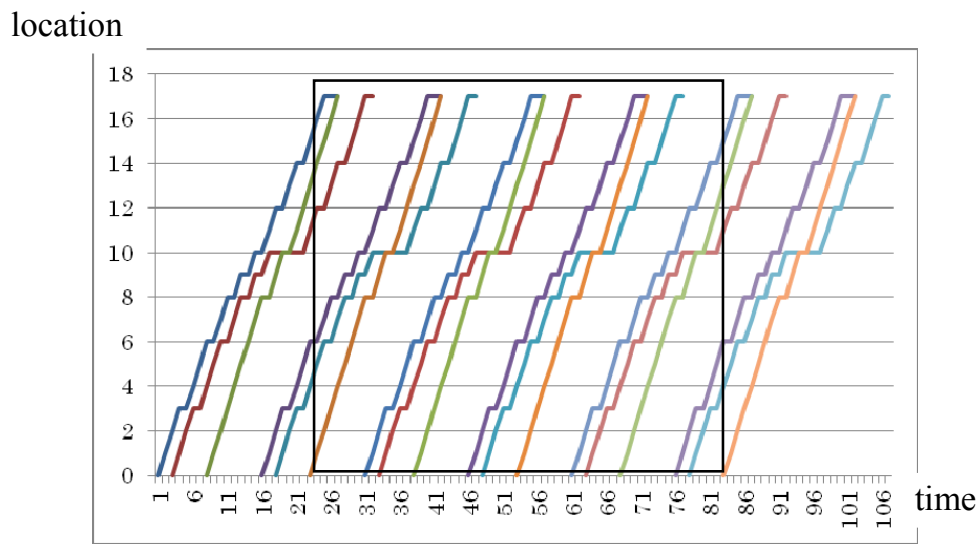

Figure 5: Repetition of train diagram.

both directions. A train diagram cycle is calculated, and the diagram is copied to show a one-hour period. This concept is shown in Figure 5.

The train diagram is expressed on a cylinder to enable an evaluation of all passengers starting and arriving at any given time. The concept of the cylinder diagram is shown in Figure 6.

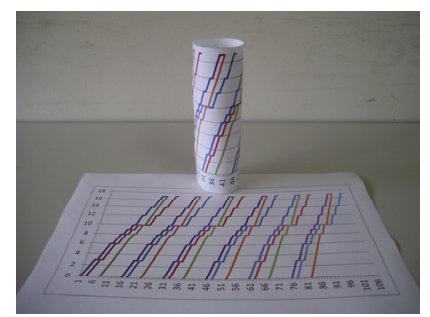

Figure 6: Train diagram on cylinder.

\section{Results and discussion}

\subsection{Line under consideration}

The line under consideration is the Tokyo Metro Tozai line which connects with the Toyo Rapid line. The line map is shown in Figure 7, and the parameters are shown in Table 1.

Passenger numbers are based on reference No. [4]. The passenger peak is at station No. 9. Stations No. 0 to No. 10 have a lot of passengers, but the number decreases from No. 11. Station No. 22 has a lot of passengers because passengers can transfer to other lines and it is the station where the Tokyo Metro Tozai line connects with the Toyo Rapid line. 


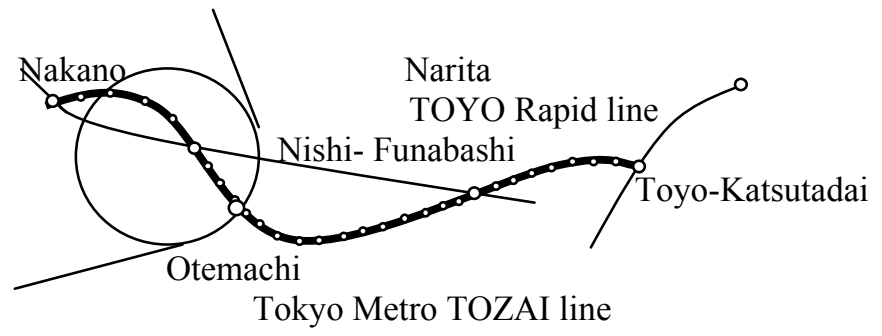

Figure 7: Tokyo Metro Tozai line - Toyo Rapid line.

Table 1: Conditions of the line under consideration.

\begin{tabular}{|l|l|}
\hline Total length & $47 \mathrm{~km}$ \\
\hline Station number & 31 stations \\
\hline $\begin{array}{l}\text { Overtaking equipment } \\
\text { number }\end{array}$ & $\begin{array}{l}7 \text { stations } \\
\text { (including terminal) }\end{array}$ \\
\hline
\end{tabular}

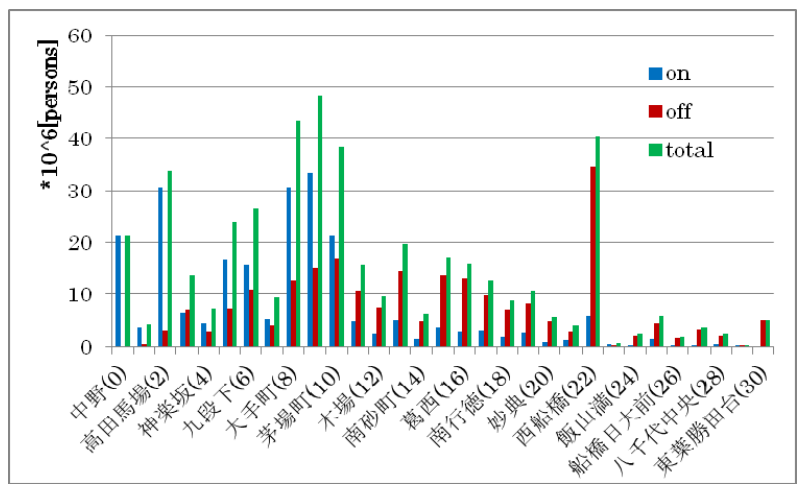

Figure 8: Passenger number at each station.

Departure delay due to too many passengers getting on or off a train is not considered for evaluation value.

During the daytime, the current operation cycle is 15 minutes, which includes one rapid train and two local trains. In reality, only the rapid train runs through to the Toyo Rapid line, but all trains run through in this study.

\subsection{Results and discussion}

A total of five stations, namely, station No. 16, 20, 21, 22 and 27 have overtaking facilities, but No. 20, 21 and 22 are next to one another, and based on 
the train interval condition, overtaking can happen only in one of the three stations. All trains have to stop at No. 22 (the border station between the two lines). The optimum combination of stopping stations is calculated for each combination of overtaking stations.

Table 2 shows the results of the average trip time and combinations of stopping and overtaking stations.

Table 2: Station combinations and average trip time.

\begin{tabular}{|l|l|l|l|}
\hline$\#$ & $\begin{array}{l}\text { Overtaking } \\
\text { station }\end{array}$ & $\begin{array}{l}\text { Stopping station (No. 0,22 and 30 are } \\
\text { added for all combinations) }\end{array}$ & $\begin{array}{l}\text { Average } \\
\text { trip } \\
\text { time[min }\end{array}$ \\
\hline 0 & & Local only & 18.77 \\
\hline 1 & 27 & $\begin{array}{l}1,2,5,6,7,8,9,10,13,15,16,17,18,19,20,21,22, \\
23,24,25,28\end{array}$ & 18.91 \\
\hline 2 & 22, & $\begin{array}{l}1,2,3,4,5,6,7,8,9,10,13,15,16,17,19,20,22,25, \\
27,28\end{array}$ & 19.03 \\
\hline 3 & 21, & $\begin{array}{l}1,2,3,4,5,6,8,9,10,13,14,15,16,17,18,19,20, \\
22,23,24,25,28\end{array}$ & 18.89 \\
\hline 4 & 20, & $\begin{array}{l}1,2,3,4,5,6,7,8,9,10,11,13,14,15,16,17,19,22, \\
24,25,28\end{array}$ & 18.90 \\
\hline 5 & 22,27 & $1,5,6,8,9,10,13,15,17,18,19,22$ & 19.17 \\
\hline 6 & 21,27 & $2,4,7,8,9,10,11,13,17,20,21,22$ & 19.35 \\
\hline 7 & 20,27 & $2,5,7,8,9,10,11,13,16,20,21,22$ & 19.22 \\
\hline 8 & 16 & $\begin{array}{l}1,2,3,4,5,6,7,8,9,10,13,15,17,18,19,20,21,22, \\
23,24,25,28\end{array}$ & 18.81 \\
\hline 9 & $16, \quad 27$ & $2,5,8,9,10,13,15,16,17,22,25$ & 18.44 \\
\hline 10 & 16,22 & $3,6,10,15,22$ & 18.57 \\
\hline 11 & 16,21 & $2,6,8,9,10,12,15,20,21,22,23$ & 21.54 \\
\hline 12 & 16,20 & $6,8,10,13,15,22,25$ & 21.90 \\
\hline 13 & $16,22,27$ & $1,2,3,4,5,10,13,15,17,21,22$ & 20.53 \\
\hline 14 & $16,21,27$ & $1,2,3,10,11,12,15,22$ & 17.71 \\
\hline 15 & $16,20,27$ & $1,2,3,5,10,15,22$ & $\begin{array}{l}1,2,3,4,5,6,7,8,9,10,11,12,13,17,22,23,24,25, \\
26,27,28,29\end{array}$ \\
\hline 16 & Real $(16,22)$ & \\
\hline 17 & 20 & & $18,23,24,25,28$ \\
\hline
\end{tabular}


For the line under consideration, the results depend strongly on the OD feature.

A combination with many stopping stations and fewer overtaking stations gives a good evaluation value. This means that the number of passengers is distributed uniformly between stopping and passing stations. Therefore, more overtaking stations lead to loss of time due to an increase in waiting time for passengers.

These results are appropriate because both No. 10 and No. 16 have the same conditions in terms of overtaking station number, but No. 10 has a smaller evaluation value than the existing operation No. 16.

Stopping stations with many passengers getting on or off are not necessarily all selected. Stopping stations are selected based on regular stopping intervals. In previous research [2], we decided the order of stopping stations based on the number of passengers but the above indicates this was not appropriate.

Regarding the evaluation value, the operation of a local train only has a short average trip time. As for the current existing overtaking facilities, No. 9-13 and No. 17 have better value than the local train only.

Concerning stopping and overtaking stations, one station cannot be a stopping and overtaking station at the same time. When the train stops and overtakes at the same time under the given OD condition, time loss is long.

Setting an overtaking station freely results in a shorter average trip time solution. This result becomes an element for facility planning.

\section{Conclusion}

To shorten the average trip time and improve the rapidity for railway operations, we adjusted stopping and overtaking stations of a rapid train.

The kinds of trains under consideration were a local and rapid train only, and a turning operation was not permitted. First, the rapid train stopping stations were determined by DP, and then the local train diagram was drawn starting from overtaking stations in both directions.

The rapid train stopping and overtaking stations were adjusted by dynamic programming. The results depended on the OD feature for the line under consideration, and it is not time-effective when passengers can change trains at a station where two trains have stopped at the same time.

In future research, we will consider the best station combination and shortening effect if the rapid train can also overtake the local train at stations where overtaking facilities do not exist.

\section{Acknowledgement}

We thank Assistant Professor Ruth Vanbaelen, Nihon University, for English language assistance. 


\section{References}

[1] M. Iguchi, Railway \& Electrical Engineering, Vol. 3, No. 4, pp. 3-6 (Apr. 1992) (in Japanese)

[2] T. Katori, T. Izumi, Y. Takahashi, "Shortening total trip time by short station dwell time and passing local trains", WIT press, Computers in Railways VIII, pp. 769-777 (Jun. 2002)

[3] T. Katori, Y. Takahashi, T. Izumi, "To Shorten Total Trip Time for Passengers by Rapid Trains Operation - Determination of the Stations where Rapid Train Stops or Passes to Local Trains used Genetic Algorithm”, IEE Japan, Vol. 125, D, No. 4, pp. 305-312 (Apr. 2005) (in Japanese)

[4] The Japan Transport Ministry, "The Year Report of Urban Transport in 2002", (Mar. 2003) (in Japanese) 